\title{
Early Neonatal Morbidity after Term Delivery: How should We respond?
}

\author{
${ }^{1}$ Milan Stanojevic, ${ }^{2}$ Lana Leko
}

\section{ABSTRACT}

Aim: The aim of this retrospective study was to investigate the influence of gestational age and mode of delivery at term on early neonatal morbidity and mortality in a tertiary maternity center in a 10-year period.

Materials and methods: The data were derived from the medical records between January 1, 2005, and December 31, 2014, from the University Hospital "Sveti Duh," Zagreb, Croatia. There were 30,363 live born term infants included in the study. The data from the medical records have been used to analyze their mode of delivery, morbidity, and mortality.

Results: Term newborn infants delivered by cesarean section (CS) had increased prevalence of lower Apgar scores, resuscitation, neonatal convulsions, and neonatal encephalopathy, respiratory pathology (except for amniotic fluid aspiration), and mechanical ventilation. Early and late neonatal deaths were more prevalent in term infants delivered by CS. The prevalence of birth trauma (except for facial nerve palsy) and hyperbilirubinemia was significantly increased in vaginally born neonates. The prevalence of perinatal infections was equal in both groups of infants. Morbidity and mortality of term newborn infants presented as prevalence per 1,000 live born, regardless of the mode of a delivery week by week from 37 through 41 weeks of gestation, were also investigated. The highest prevalence for most of the observed parameters were at 37 to 41 weeks of gestation, while the lowest prevalence was observed at a gestational age between 39 and 40 weeks. This was not the case for the 1 st and the 5th minute 4 to 7 Apgar scores, birth injuries, respiratory pathology, and late neonatal deaths.

Conclusion: Early-term delivery was connected with more morbidity and mortality in the early neonatal period. It seems that the best gestational age to be born is at 39 to 40 weeks of gestation. Mode of delivery at term counts as well, showing that vaginal delivery at term had the lowest risk of morbidity and mortality.

Keywords: Morbidity, Neonate, Term delivery

How to cite this article: Stanojevic M, Leko L. Early Neonatal Morbidity after Term Delivery: How should We respond? Donald School J Ultrasound Obstet Gynecol 2016;10(2):180-184

Source of support: Nil

Conflict of interest: None

\footnotetext{
${ }^{1}$ Professor, ${ }^{2}$ Resident

1,2Department of Obstetrics and Gynecology, Medical School University of Zagreb, Neonatal Unit, University Hospital "Sveti Duh", Zagreb, Croatia
}

Corresponding Author: Milan Stanojevic, Professor, Department of Obstetrics and Gynecology, Medical School University of Zagreb, Neonatal Unit, University Hospital "Sveti Duh", Sveti duh 64, 10000 Zagreb, Croatia, Phone: +385 13712316 , e-mail: milan.stanojevic@optinet.hr

\section{INTRODUCTION}

Fetal maturation and duration of pregnancy are among the most controversial subjects in perinatal medicine. For many years, efforts have been made to predict the best possible time for delivery of the fetus in terms of its maturity and unrestricted readiness for extrauterine life both at the limits of viability and at so-called term. Many clinical methods have been developed to assess maternal and fetal readiness for delivery like Bishop's score, amnioscopy and visualization of amniotic fluid, amniocentesis and lung maturation and gestational age assessment, visual assessment and histopathology of placenta, and postnatal clinical assessment of gestational age. ${ }^{1-5}$ Besides genetic factors of the mother and the fetus, environment and microbiome have a strong influence on the fetal maturity. ${ }^{6}$ The embryo and fetus are highly responsive to the gestational environment. Glucocorticoid levels are tightly regulated in the fetal circulation, maintained at low levels during pregnancy and increasing rapidly at the end of gestation. ${ }^{6}$ Glucocorticoids represent an important class of developmental signals and they are critical for the development of organs like the lungs, brain, and kidney. ${ }^{6}$ Glucocorticoids may drive regulation of gene transcription through altered epigenetic pathways and their production can be increased by fetal and maternal stress or through exposure of the fetus and the mother to the synthetic glucocorticoids. ${ }^{6}$ If the fetus is mature enough to be born even at term, this can affect its outcome in terms of morbidity and even mortality. ${ }^{6}$

The aim of the retrospective study was to investigate the influence of gestational age and mode of delivery at term on early neonatal morbidity and mortality in a tertiary maternity center at the 10-year period.

\section{MATERIALS AND METHODS}

This is a retrospective study of all term infants born in the 10-year period between January 1, 2005 and December 31, 2014, at University Hospital “Sveti Duh," Zagreb, Croatia. There were 30,363 live born term infants included in the study. The data from medical records have been used to analyze their mode of delivery, morbidity, and mortality. Birth weight, birth length, the 1st and the 5th minute Apgar scores are presented in Table 1 for 
Early Neonatal Morbidity after Term Delivery

Table 1: Characteristics of term infants born between 37 and 41 weeks of gestation at the University Hospital "Sveti Duh," Zagreb, Croatia in the 10-year period (from 2005 to 2014)

\begin{tabular}{|c|c|c|c|c|c|}
\hline \multirow{2}{*}{$\begin{array}{l}\text { Gestational } \\
\text { age (weeks) }\end{array}$} & \multirow{2}{*}{$\begin{array}{l}\text { Mode of delivery and number of } \\
\text { infants (male/female) }\end{array}$} & Birth weight (gm) & Birth length $(\mathrm{cm})$ & $\begin{array}{l}\text { 1st minute } \\
\text { Apgar score }\end{array}$ & $\begin{array}{l}\text { 5th minute } \\
\text { Apgar score }\end{array}$ \\
\hline & & \multicolumn{4}{|c|}{ Mean \pm standard deviation (range) } \\
\hline & Vaginally $N=1,109(558 / 551)$ & $2,970 \pm 389(1,760-4,550)$ & $48.6 \pm 1.9(41-53)$ & $9.8 \pm 0.6(4-10)$ & $10 \pm 0.3(4-10)$ \\
\hline \multirow[t]{5}{*}{37} & $\begin{array}{l}\text { Cesarean section } \mathrm{N}=502 \\
(249 / 253)\end{array}$ & $2,825 \pm 470(1,330-5,100)$ & $48.0 \pm 2.3(39-56)$ & $9.7 \pm 1.0(1-10)$ & $9.9 \pm 0.5(1-10)$ \\
\hline & Subtotal $N=1,611(807 / 804)$ & $2,925 \pm 421(1,330-5,100)$ & $48.5 \pm 2.0(39-56)$ & $9.8 \pm 0.8(1-10)$ & $9.9 \pm 0.5(1-10)$ \\
\hline & Vaginally $N=2,541(1,289 / 1,252)$ & $3,204 \pm 401(1,220-5,100)$ & $49.5 \pm 1.9(39-59)$ & $9.9 \pm 0.4(5-10)$ & $10 \pm 0.1(8-10)$ \\
\hline & $\begin{array}{l}\text { Cesarean section } N=994 \\
(471 / 523)\end{array}$ & $3,202 \pm 455(1,330-4,940)$ & $49.2 \pm 1.9(38-58)$ & $9.8 \pm 0.8(0-10)$ & $9.9 \pm 0.5(1-10)$ \\
\hline & Subtotal $N=3,535(1,760 / 1,775)$ & $3,204 \pm 417(1,220-5,100)$ & $49.5 \pm 1.9(38-58)$ & $9.9 \pm 0.5(0-10)$ & $10 \pm 0.3(1-10)$ \\
\hline \multirow[t]{3}{*}{39} & Vaginally $N=6,934(3,396 / 3,538)$ & $3,437 \pm 391(2,100-5,140)$ & $50.5 \pm 1.8(39-59)$ & $9.9 \pm 0.4(1-10)$ & $10 \pm 0.2(1-10)$ \\
\hline & $\begin{array}{l}\text { Cesarean section } N=2,056 \\
(1,048 / 1,008)\end{array}$ & $3,489 \pm 431(1,730-5,150)$ & $50.2 \pm 1.8(42-57)$ & $9.9 \pm 0.5(5-10)$ & $10 \pm 0.2(8-10)$ \\
\hline & Subtotal $N=8,990(4,444 / 4,546)$ & $3,449 \pm 401(1,730-5,150)$ & $50.4 \pm 1.8(39-59)$ & $9.9 \pm 0.4(1-10)$ & $10 \pm 0.2(1-10)$ \\
\hline \multirow[t]{3}{*}{40} & Vaginally $N=12,687(6,609 / 6,078)$ & $3,634 \pm 404(2,300-5,700)$ & $51.3 \pm 1.8(44-59)$ & $9.9 \pm 0.4(1-10)$ & $10 \pm 0.2(2-10)$ \\
\hline & $\begin{array}{l}\text { Cesarean section } N=2,067 \\
(1,200 / 867)\end{array}$ & $3,729 \pm 460(2,340-5,630)$ & $51.3 \pm 1.8(45-58)$ & $9.8 \pm 0.7(0-10)$ & $10 \pm 0.4(2-10)$ \\
\hline & Subtotal $N=14,754(7,809 / 6,945)$ & $3,648 \pm 414(2,300-5,700)$ & $51.3 \pm 1.8(44-59)$ & $9.9 \pm 0.5(0-10)$ & $10 \pm 0.2(2-10)$ \\
\hline \multirow[t]{3}{*}{41} & Vaginally $N=1,292(688 / 604)$ & $3,723 \pm 440(2,420-5,020)$ & $51.8 \pm 1.9(45-58)$ & $9.9 \pm 0.4(5-10)$ & $10 \pm 0.2(5-10)$ \\
\hline & $\begin{array}{l}\text { Cesarean section } N=231 \\
(131 / 100)\end{array}$ & $3,709 \pm 469(2,080-5,300)$ & $51.7 \pm 1.9(43-56)$ & $9.8 \pm 0.9(0-10)$ & $9.9 \pm 0.6(2-10)$ \\
\hline & Subtotal $N=1,473(819 / 654)$ & $3,720 \pm 444(2,080-5,300)$ & $51.8 \pm 1.9(43-58)$ & $9.9 \pm 0.5(0-10)$ & $10 \pm 0.3(2-10)$ \\
\hline $37-41$ & $30,363(15,639 / 14,724)$ & $3,502 \pm 460(1,220-5,700)$ & $50.7 \pm 2.0(38-59)$ & $9.9 \pm 0.5(0-10)$ & $10 \pm 0.2(1-10)$ \\
\hline
\end{tabular}

newborn infants from 37 to 41 weeks of gestation week by week. Gestational age was estimated on grounds of the last menstrual period, early ultrasound, postnatal clinical assessment using Farr's criteria if there was the difference between early ultrasound estimation of gestational age and gestational age estimated using last menstrual period. ${ }^{7}$ Morbidity included Apgar scores in the 1 st and the 5 th minute of $\leq 3$, and from 4 to 7 , need for resuscitation after delivery, neonatal encephalopathy using prenatal criteria by American College of Obstetricians and Gynecologists and American Academy of Pediatrics, ${ }^{8}$ and clinical criteria by Sarnat and Sarnat, ${ }^{9}$ confirmed by brain ultrasound finding of increased echogenicity of the brain, neonatal convulsions, clinically diagnosed birth trauma (clavicle fracture, cephalhematoma, Erb's brachial plexus injury, peripheral facial nerve palsy) and epidural and subdural hematoma using multisliced computerized tomography, respiratory morbidity (including transient tachypnea of the newborn, amniotic fluid aspiration syndrome, meconium aspiration syndrome, congenital pneumonia, need for treatment with nasal continuous positive airway pressure (CPAP) or mechanical ventilation, and pneumothorax), workup for neonatal infections (proved Streptococcus group B early infection, bacteriuria, or urinary tract infection), hyperbilirubinemia according to the adapted criteria of American Academy of Pediatrics, ${ }^{10}$ and early and late neonatal mortality.

\section{STATISTICAL METHODS}

The data were presented as means and standard deviations and ranges and frequencies. The Chi-square test with Yates correction ${ }^{11}$ was used to assess the difference between the frequencies. Pearson correlation coefficient ${ }^{12}$ was calculated for the correlations between the gestational age and observed prevalence.

\section{RESULTS}

Results are shown in Tables 2 and 3. Morbidity and mortality between term newborn infants (37-41 weeks of gestation) dependent on the mode of delivery (born vaginally or by cesarean section (CS) in the 10-year period at the University Hospital Sveti Duh, Zagreb, Croatia, are compared in Table 2. Morbidity and mortality are dependent on the mode of delivery. Term newborn infants delivered by CS were more often with lower Apgar scores, prone to resuscitation, had more often neonatal convulsions and neonatal encephalopathy, respiratory pathology (except for amniotic fluid aspiration), were more often mechanically ventilated, while nasal CPAP treatment was not statistically more often used. The possibility of early and late neonatal death is more often observed in term infants delivered by CS. The frequency of birth trauma (except for facial nerve palsy) and hyperbilirubinemia is significantly more often observed in vaginally born neonates. The 
Table 2: Comparison of morbidity and mortality between term newborn infants ( 37 to 41 weeks of gestation) born vaginally or by cesarean section in the 10-year period at the University Hospital Sveti Duh, Zagreb, Croatia

\begin{tabular}{|c|c|c|c|c|}
\hline \multirow[b]{2}{*}{ Parameter } & \multicolumn{2}{|c|}{ Number of infants } & \multirow[b]{2}{*}{$x^{2}$} & \multirow[b]{2}{*}{$p$-value } \\
\hline & Vaginal $N=24,513$ & Cesarean section $N=5,850$ & & \\
\hline 1st minute Apgar score $\leq 3$ & 6 & 15 & 33.48 & 0.0001 \\
\hline 1st minute Apgar score 4-7 & 37 & 36 & 40.56 & 0.0001 \\
\hline 5th minute Apgar score $\leq 3$ & 1 & 7 & 19.82 & 0.0001 \\
\hline 5th minute Apgar score $4-7$ & 23 & 18 & 14.47 & 0.0001 \\
\hline Resuscitation & 22 & 26 & 35.43 & 0.0001 \\
\hline Neonatal encephalopathy & 16 & 14 & 12.78 & 0.0003 \\
\hline Neonatal convulsions & 27 & 16 & 7.79 & 0.005 \\
\hline Total birth trauma & 1,160 & 36 & 210.5 & 0.0001 \\
\hline Subdural/epidural hematoma & 3 & 4 & 4.25 & 0.039 \\
\hline Clavicle fracture & 273 & 1 & 62.29 & 0.0001 \\
\hline Cephalhematoma & 800 & 26 & 140.72 & 0.0001 \\
\hline Brachial plexus birth injury (Erb) & 33 & 0 & 6.69 & 0.009 \\
\hline Facial nerve birth palsy (Bell) & 15 & 5 & 0.134 & 0.71 \\
\hline Total respiratory pathology & 68 & 46 & 31.36 & 0.0001 \\
\hline Transient tachypnea of the newborn & 28 & 19 & 12.22 & 0.0005 \\
\hline Amniotic fluid aspiration syndrome & 6 & 0 & 0.46 & 0.497 \\
\hline Meconium aspiration syndrome & 12 & 12 & 12.68 & 0.0004 \\
\hline Congenital pneumonia & 22 & 15 & 9.45 & 0.0021 \\
\hline Mechanical ventilation & 8 & 8 & 7.84 & 0.005 \\
\hline Nasal CPAP & 6 & 3 & 0.419 & 0.52 \\
\hline Pneumothorax & 2 & 4 & 5.88 & 0.015 \\
\hline Perinatal infection workup & 110 & 33 & 1.006 & 0.29 \\
\hline Streptococcus group B infections & 10 & 2 & 0.052 & 0.82 \\
\hline Urinary tract infections & 17 & 5 & 0.02 & 0.89 \\
\hline Hyperbilirubinemia & $2,049(8.4 \%)$ & $396(6.7 \%)$ & 15.90 & 0.0001 \\
\hline Death $\leq 168$ hours & 8 & 10 & 13.00 & 0.0003 \\
\hline Death $\geq 169$ hours & 2 & 4 & 5.89 & 0.015 \\
\hline
\end{tabular}

CPAP: Continuous positive airway pressure

frequency of perinatal infections was equal in both groups of infants.

Morbidity and mortality of term newborn infants presented as prevalence per 1,000 live born, regardless of the mode of a delivery week by week from 37 through 41 weeks of gestation in the 10 years period at the University Hospital Sveti Duh, Zagreb, Croatia, is shown in Table 3. The highest prevalence for the most of the observed parameters was at 37 to 41 weeks of gestation, while the lowest was at gestational age of 39 to 40 weeks. This was not the case for the 1st and the 5th minute Apgar scores from 4 to 7 , birth injuries, respiratory pathology, and late neonatal deaths (after 169 hours of life).

\section{DISCUSSION}

If we look at the characteristics of term newborns presented in Table 1 week by week, then the CS rate at 37 weeks of gestation was $31.2 \%$, at 38 weeks $28.1 \%$, at 39 weeks $22.9 \%$, at 40 weeks $14.0 \%$, and at 41 weeks $15.7 \%$. Cesarean section rate is decreasing with increasing gestational age from 37 to 40 weeks of gestation, while at 41 weeks it is slightly increased compared with that at
40 weeks of gestation. No differences have been observed between the birth weights, lengths, Apgar scores within 1 week of gestation regardless of the mode of delivery and the gender of the infants (data not shown). At each gestational age, there has been increasing birth weight and birth length with increasing gestational age from 37 through 41 weeks of gestation as has been shown in other studies. ${ }^{13,14}$

Current obstetrical practice guidelines emphasize vaginal birth as the preferred delivery method whenever possible, despite the fact that CS rate is increasing in developed and developing countries. ${ }^{15,16}$ It is known that term infants born by CS have more health problems in the early neonatal period compared with vaginally born neonates, and that early-term infants have more health problems than later with the effect even on mortality. ${ }^{17}$ In our study, neonatal deaths were more frequent in neonates born by CS and in neonates born at 37 weeks of gestation. Recent evidence from studies based on a mode of delivery has pointed toward increased morbidity associated with early-term CS births (37 weeks) compared with term neonates (39-40 weeks). ${ }^{18}$ Compared with term infants, early-term neonates had significantly higher 
Early Neonatal Morbidity after Term Delivery

Table 3: Morbidity and mortality of term newborn infants regardless of the mode of delivery week by week from 37 through 41 weeks of gestation in the 10-year period at the University Hospital Sveti Duh, Zagreb, Croatia

\begin{tabular}{|c|c|c|c|c|c|c|c|}
\hline \multirow[b]{2}{*}{ Parameter } & \multicolumn{5}{|c|}{ Prevalence per 1,000 live births at gestational age of weeks } & \multirow{2}{*}{$\begin{array}{l}\text { Pearson's } \\
\text { correlation } \\
\text { coefficient }(r)\end{array}$} & \multirow{2}{*}{$\begin{array}{l}\text { Cumulative } \\
\text { prevalence per } \\
1,000 \text { live births } \\
N=30,363\end{array}$} \\
\hline & $\begin{array}{l}37 \\
N=1,611\end{array}$ & $\begin{array}{l}38 \\
N=3,535\end{array}$ & $\begin{array}{l}39 \\
N=8,990\end{array}$ & $\begin{array}{l}40 \\
N=14,754\end{array}$ & $\begin{array}{l}41 \\
N=1,473\end{array}$ & & \\
\hline 1st minute Apgar score $\leq 3$ & 3.76 & 0.8 & 0.3 & 0.3 & 2.0 & -0.43 & 0.7 \\
\hline 1st minute Apgar score $4-7$ & 12.4 & 2.3 & 1.3 & 2.1 & 1.3 & -0.74 & 2.4 \\
\hline 5th minute Apgar score $\leq 3$ & 1.9 & 0.6 & 0 & 0.07 & 1.3 & -0.33 & 0.3 \\
\hline 5th minute Apgar score 4-7 & 7.4 & 0.8 & 0.9 & 1.1 & 1.3 & -0.66 & 1.4 \\
\hline Resuscitation & 6.2 & 2.0 & 1.0 & 1.2 & 2.6 & -0.60 & 1.6 \\
\hline Neonatal encephalopathy & 2.5 & 0.3 & 0.7 & 0.8 & 4.6 & 0.42 & 1.0 \\
\hline Neonatal convulsions & 1.9 & 2.3 & 0.8 & 1.3 & 3.9 & 0.40 & 1.4 \\
\hline Subdural/epidural hematoma & 0.6 & 0.3 & 0 & 0.2 & 0.7 & 0.05 & 0.2 \\
\hline Clavicle fracture & 5.6 & 7.6 & 3.2 & 12.8 & 13.8 & 0.75 & 9.0 \\
\hline Cephalhematoma & 17.4 & 35 & 27 & 30 & 40.7 & 0.75 & 27.2 \\
\hline Brachial plexus birth palsy (Erb) & 1.2 & 0.3 & 1.0 & 1.3 & 1.3 & 0.45 & 1.1 \\
\hline Facial nerve birth palsy (Bell) & 0.6 & 1.1 & 0.7 & 0.6 & 0 & -0.68 & 0.7 \\
\hline Transient tachypnea of the newborn & 9.9 & 3.4 & 0.7 & 0.7 & 2.0 & -0.76 & 1.5 \\
\hline Amniotic fluid aspiration syndrome & 1.9 & 0 & 0.1 & 0.1 & 0 & -0.71 & 0.2 \\
\hline Meconium aspiration syndrome & 0 & 0.3 & 0.7 & 0.7 & 3.9 & 0.82 & 0.8 \\
\hline Congenital pneumonia & 2.5 & 1.1 & 0.6 & 1.3 & 3.3 & 0.26 & 1.2 \\
\hline Mechanical ventilation & 2.5 & 0.8 & 0.3 & 0.3 & 0.7 & -0.71 & 0.5 \\
\hline Nasal CPAP & 2.5 & 0.6 & 0 & 0.1 & 1.3 & -0.44 & 0.3 \\
\hline Pneumothorax & 0.6 & 0.6 & 0.1 & 0.1 & 0.7 & -0.16 & 0.2 \\
\hline Perinatal infection workup & 9.9 & 4.0 & 3.8 & 4.6 & 7.2 & -0.29 & 4.7 \\
\hline Streptococcus group B infections & 0.6 & 1.1 & 0.1 & 0.3 & 0.7 & -0.25 & 0.4 \\
\hline Hyperbilirubinemia & 218 & 148 & 106 & 36 & 68 & -0.91 & 81.0 \\
\hline Death $\leq 168$ hours & 2.5 & 0.9 & 0.7 & 0.2 & 1.3 & -0.57 & 0.59 \\
\hline Death $\geq 169$ hours & 2.5 & 0 & 0.2 & 0 & 0 & -0.72 & 0.20 \\
\hline
\end{tabular}

CPAP: Continuous positive airway pressure

risks for the following: Lower Apgar scores, a need for resuscitation, a need for respiratory support, treatment with mechanical ventilation, more common birth injuries, as well as neonatal encephalopathy and convulsions. Delivery by CS was common among early-term births with increased morbidity compared with term births. ${ }^{18}$ In some studies, it has been proved that early-term infants were more likely to require neonatal intensive care and to be born by CS. ${ }^{19}$

Besides increased rate of respiratory pathology in the early neonatal period, it has been proved that earlyterm delivery is associated with respiratory morbidity in childhood, while CS also appears to be associated with increased neonatal morbidity and future development of respiratory symptoms. ${ }^{20}$ It seems that early-term birth can have long-term neurodevelopmental consequences with lower general cognitive scores persisting into adulthood. ${ }^{21}$

\section{CONCLUSION}

Early-term delivery is connected with more morbidity and mortality in the early neonatal period. It seems that the best gestational age to be born is at 39 to 40 weeks of gestation, while 37 to 38 and 41 weeks of gestation are connected with more prevalent health problems in the early neonatal period. Mode of delivery at term is also very important, showing that vaginal delivery at term has the lowest risk for morbidity and mortality, while the risk is increasing with decreasing gestational age from 37 to 40 weeks and again increasing at 41 weeks of gestation.

\section{REFERENCES}

1. Bajpai N, Bhakta R, Kumar P, Rai L, Hebbar S. Manipal Cervical Scoring System by transvaginal ultrasound in predicting successful labour induction. J Clin Diagn Res 2015 May;9(5):QC04-QC09.

2. Mayer C, Joseph KS. Fetal growth: a review of terms, concepts and issues relevant to obstetrics. Ultrasound Obstet Gynecol 2013 Feb;41(2):136-145.

3. Wijnberger LD, de Kleine M, Voorbij HA, Arabin B, Bruinse HW, Visser GH, Bossuyt PM, Mol BW. Prediction of fetal lung immaturity using gestational age, patient characteristics and fetal lung maturity tests: a probabilistic approach. Arch Gynecol Obstet 2010 Jan;281(1):15-21.

4. Vinnars MT, Papadogiannakis N, Nasiell J, Holmström G, Westgren M. Placental pathology in relation to stillbirth and neonatal outcome in an extremely preterm population: a prospective cohort study. Acta Obstet Gynecol Scand 2015 Jun;94(6):584-590. 
5. Sasidharan K, Dutta S, Narang A. Validity of New Ballard Score until 7th day of postnatal life in moderately preterm neonates. Arch Dis Child Fetal Neonatal Ed 2009 Jan;94(1): F39-F44.

6. Constantinof A, Moisiadis VG, Matthews SG. Programming of stress pathways: a transgenerational perspective. J Steroid Biochem Mol Biol 2015 Oct 22;pii:S0960-0760(15)30110-2.

7. Opara P. Gestational age assessment in the newborn-a review. Internet J Pediatr Neonatol 2009;12(2). Available from: http://print.ispub.com/api/0/ispub-article/7783.

8. Task Force on Neonatal Encephalopathy and Cerebral Palsy Staff American College of Obstetricians and Gynecologists with American Academy of Pediatrics Staff. Neonatal Encephalopathy and Cerebral Palsy: Defining the Pathogenesis and Pathophysiology. Washington, DC: The American College of Obstetricians and Gynecologists; 2003.

9. Sarnat HB, Sarnat MS. Neonatal encephalopathy following fetal distress. A clinical and electroencephalographic study. Arch Neurol 1976 Oct;33(10):696-705.

10. American Academy of Pediatrics Subcommittee on Hyperbilirubinemia. Management of hyperbilirubinemia in the newborn infant 35 or more weeks of gestation. Pediatrics 2004 Jul;114(1):297-316.

11. Available from: http://graphpad.com/quickcalcs/ contingency1/

12. Available from: http://www.endmemo.com/statistics/ cc.php

13. Villar J, Cheikh Ismail L, Victora CG, Ohuma EO, Bertino E, Altman DG, Lambert A, Papageorghiou AT, Carvalho M, Jaffer YA, et al. International standards for newborn weight, length, and head circumference by gestational age and sex: the Newborn Cross-Sectional Study of the INTERGROWTH-21st Project. Lancet 2014 Sep 6;384(9946):857-868.

14. Alexander AM, George K, Muliyil J, Bose A, Prasad JH. Birthweight centile charts from rural community-based data from southern India. Indian Pediatr 2013 Nov8;50(11):1020-1024.

15. Morel AA, Bailey SM, Shaw G, Mally P, Malhotra SP. Measurement of novel biomarkers of neuronal injury and cerebral oxygenation after routine vaginal delivery versus cesarean section in term infants. J Perinat Med 2014 Nov;42(6):705-709.

16. Visser GH. Women are designed to deliver vaginally and not by cesarean section: an obstetrician's view. Neonatology 2015;107(1):8-13.

17. Wu CS, Sun Y, Nohr EA, Olsen J. Trends in all-cause mortality across gestational age in days for children born at term. PLoS One 2015 Dec14;10(12):e0144754.

18. Sengupta S, Carrion V, Shelton J, Wynn RJ, Ryan RM, Singhal K, Lakshminrusimha S. Adverse neonatal outcomes associated with early-term birth. JAMA Pediatr 2013 Nov;167(11):1053-1059.

19. Mally PV, Agathis NT, Bailey SM. Early term infants are at increased risk of requiring neonatal intensive care. World J Pediatr 2016 Feb;12(1):76-81.

20. Kotecha SJ, Gallacher DJ, Kotecha S. The respiratory consequences of early-term birth and delivery by caesarean sections. Paediatr Respir Rev 2015 Dec 23;pii:S15260542(15)00151-7.

21. Chan E, Leong P, Malouf R, Quigley MA. Long-term cognitive and school outcomes of late-preterm and early-term births: a systematic review. Child Care Health Dev 2016 Feb 10. doi:10.1111/cch.12320. 